\title{
Comparative Study of Traditional Network Marketing and E-Commerce Marketing Based on Cloud Computing
}

\author{
Min Yin, Sheng Liu* \\ School of Management, Shanghai University of Engineering Science, Shanghai. \\ Email: echoyin021@126.com, "1s6601@sina.com
}

Received December $18^{\text {th }}, 2013$; revised January $18^{\text {th }}, 2014$; accepted January $25^{\text {th }}, 2014$

Copyright (c) 2014 Min Yin, Sheng Liu. This is an open access article distributed under the Creative Commons Attribution License, which permits unrestricted use, distribution, and reproduction in any medium, provided the original work is properly cited. In accordance of the Creative Commons Attribution License all Copyrights (c) 2014 are reserved for SCIRP and the owner of the intellectual property Min Yin, Sheng Liu. All Copyright (C) 2014 are guarded by law and by SCIRP as a guardian.

\section{ABSTRACT}

Cloud computing aims to integrate more than one relatively low-cost computing entities into a perfect system of powerful computing capabilities, and distribute this powerful computing capabilities to end-users by the advanced business model. Traditional network marketing has played an important role in the e-commerce industry, bringing invaluable wealth for online transactions, but with the continuous improvement of people's living standard, traditional marketing methods can no longer meet the market requirements. This paper compares the difference between traditional network marketing and cloud marketing based on cloud computing, and creates a new cloud marketing model C-Marketing. Then the advantages of C-Marketing as a new hot spot in marketing are discussed. Finally some suggestions for improvement are proposed based on this.

\section{KEYWORDS}

\section{Cloud Computing; Network Marketing; C-Marketing}

\section{Introduction}

According to the definition of AAA (American Marketing Association), marketing is the organizational function and procedure to create, communicate and send the value to customers, and manage customer relationships so that the organization and its stakeholders can obtain the benefits. Network Marketing was born in the 1990s, and has been developed in the late 20th century until now, which gets along with the background and development of three main areas: the development of network information technology, changing consumer values and increasing market competition. Immediately after distributed computing, grid computing, utility computing, P2P computing, and the market-oriented computing, cloud computing has been deepening in various industries. It is a problem e-commerce business which needs to be solved to develop cloud marketing based on cloud computing. Traditional network marketing is also built on the basic business realizations, such as improving information flow, capital flow, logistics and other aspects, and even *Corresponding author.

creating a online transaction site, which are far from being able to meet consumer requirements in today's online transactions. With the development of network technology and the rising network transactions, expectations of consumers' network consuming are much larger than those of the traditional underline transactions. This article compares the traditional network marketing and cloud marketing, points out the problem of the traditional network marketing, and then gives the advantages of cloud marketing, and finally makes recommendations for enterprises about cloud marketing.

\section{Research Status}

Network Marketing occurred earlier than the cloud marketing, which is an important way to connect traditional marketing and recent network technology, the traditional network marketing has played an important role in the early stages of e-commerce. And similar to traditional marketing, network marketing research is also focused on the study of consumer behavior and network marketing methods, but in the early days, there are a lot of 
comparisons of internet marketing and traditional marketing. As Kang yun [1] proposed the development conditions of network marketing and noted that it would have some impact on traditional marketing, but would not replace it. Wang chao [2] thinks that under the new economic situation, network marketing has a huge advantage. Zhang Ruijuan [3] believes that the change trend of e-commerce network marketing should make a whole plan, and sophisticate safety technology by taking advantage of third-party e-commerce platform. As for internet consumer behavior, Zhang qiong [4] obtained statistical data by designing questionnaires to build a model of consumer behavior attitude, and illustrated that attitude-behavior theory and technology innovation diffusion theory is still valid in B2C e-commerce environment through hypothesis testing of the model. Liu Meilian and Li Zhicheng [5] established a model of consumer attitude and behavior in e-commerce environment on the basis of TRA, TPB and TAM theories. And for behavior patterns of consumers in group buying on internet, Wei Yang [6] affirmed that the advantages of group buying and consumer problems are: consumer spending cluster; experience the discount; consumer impulse spending, spawned "group on slaves" and more participation, less consumption.

For problems in the development of network marketing, scholars have put forward their own point of view, such as Cao Ping [7] summed the restrict elements of the network marketing development on the basis of studying it in the article of research on the development and countermeasures of network marketing of China. Young Zhi and Gao Li [8] proposed SME network marketing innovation model in their literature, and pointed out the problems of its development, they also gave relevant countermeasures. About SME network marketing problems, Tao Wei [9] pointed out the problems in the development process as well. Another research focus is the issue of e-commerce network marketing channel, Zhang Jingjing et al. [10] studied on the joint distribution of e-commerce research more comprehensive, which summed up the features, status and mode of the joint distribution of e-commerce, which gives a lot help for this study. Ren Yan [11] proposed the establishment of online marketing channels on the base of integrated network marketing, software marketing and direct marketing.

Starting from cloud computing, IBM Corporation announced plans for cloud computing [12] in late 2007, then the concept of cloud computing appeared in front of the public and in its technical white paper "Cloud Computing" [13] the cloud was defined as: "cloud computing is used to describe a system platform or one type of application. A cloud computing platform demands dynamically provision, configuration, reconfigure, deprovision and so on. Another important issue of cloud application is about security issue, literature [14] proposed a clientbased privacy data management, reduced the risks of cloud computing application by reducing the transmission of sensitive data, preventing leakage and loss of sensitive data under different scenarios. This shows that we should consider security policies in the early of cloud design [15], while there is also a need to deliver the message, share information and interact about the data between the user and service provider of the internet. But the distributed architecture of cloud computing makes the security issues more complex. Literature [16-18] ensured the security of cloud mode from the perspective of network topology, secure data format and data transmission congestion control. As the increasingly widespread of cloud computing services, data visibility is different for different users and service providers, it needs flexible access control mechanisms [19-21], traditional access control methods can no longer fully adapt to the new environment. In cloud computing environment [22], semantic access control policy language is used to describe access policy design access control oriented ontology system based on this language as to enhance interoperability while ensuring data security, which is a kind of application combined cloud computing and semantic web technology.

\section{Cloud Marketing and Network Marketing}

\subsection{Development of Network Marketing}

Network marketing takes internet as its media, which is a new marketing mode by using the message of words and internet interactivity to achieve marketing objectives. Simply put, network marketing takes internet as its main means so as to achieve a certain marketing campaign marketing purposes. Figure 1 shows the scale of ecommence network marketing in China between 2010 and 2016, showing that there is a rapid development of internet marketing, but as the technology is going mature, network marketing will eventually get a stabilized state, the level of the existing network marketing get difficult to meet customer needs. Enterprises need to introduce new applications platform and big data technologies such as cloud computing to launch a new marketing campaign to be able to guarantee the development of e-commerce as well as healthy and stable development of underline economy.

\subsection{Development of Cloud Computing}

Recently, cloud computing get a rapid development, Figure 2 displays data from research of cloud computing, it shows the 2011 personal cloud users grew 804\% compared with 2010 when cloud computing began to be used in China, and forecast cloud computing scale for the 


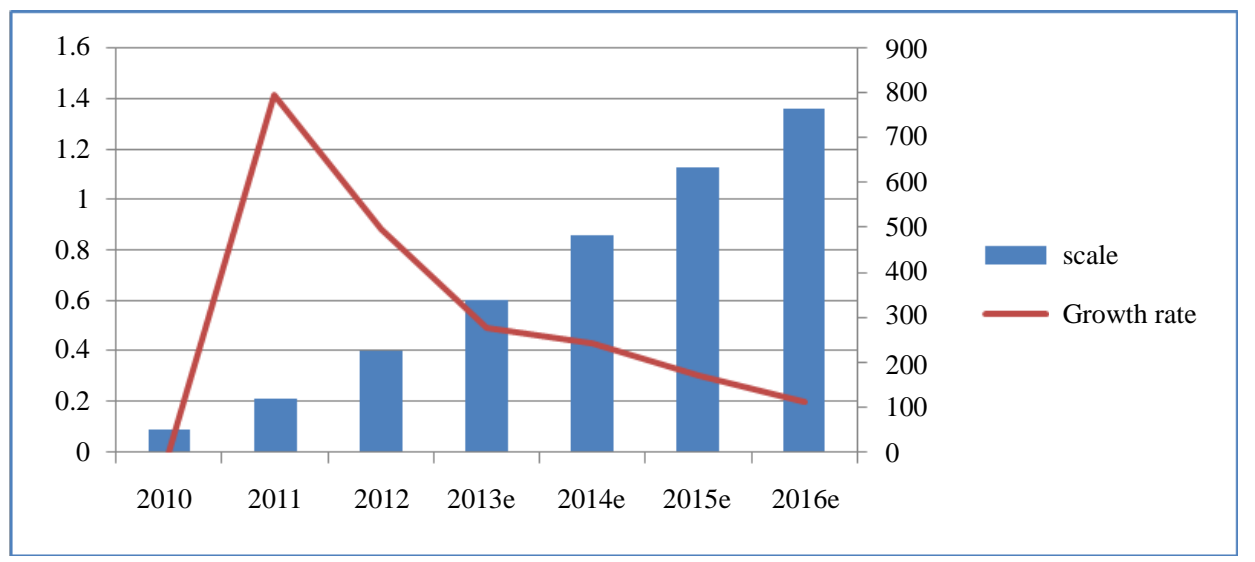

Figure 1. Scale of e-commence network marketing in China between 2010 and 2016. Source: Iresearch.

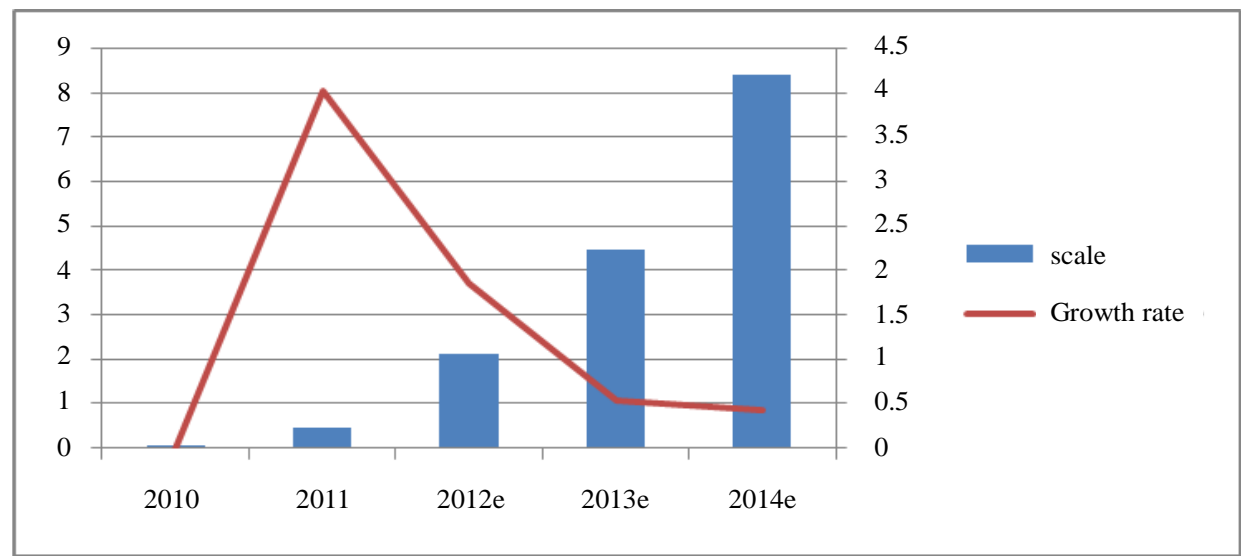

Figure 2. Scale of cloud storage in China between 2010 and 2016. Source: Iresearch.

coming years based on practical application, indicating that cloud computing will gradually be accepted and get a lot of applications in the next few years.

\subsection{Distinction between Cloud Marketing and Network Marketing}

There are a few academic research literatures on cloud marketing this moment, this paper try to compare cloud marketing from the traditional network marketing features in order to make some contribution both in practice and in the development of academic about cloud marketing. First, Figure 3 shows there are big differences between traditional marketing and online marketing and cloud marketing of the corporate marketing methods.

\section{Innovative Cloud Marketing}

\subsection{C-Marketing}

In essence, cloud marketing is different with network marketing, which is to implement marketing techniques on the basis of cloud computing. Figure 4 is a simple cloud marketing program based on Mapreduce and mar- keting decision support model (MDSS), which can be seen it is not just take advantage of network or end apps to promote products as traditional network marketing. We name it C-Marketing.

According to Kotler's sustainable marketing enterprise model (SME) [23], we think we can design a sustainable cloud marketing model (SCM), which means to perfect marketing model based on cloud computing. Cloud computing applications will not cause major changes in the SME model, what are discussed here are mainly about the marketing model. Figure 5 is the marketing model in Kotler's book. And in the figure, 4C means change, competitor, customer and the company; E3 represents exploration, engagement and execution; STV is for strategy, tactics and values. PCS represents people, consumer and shareholder.

We can learn that the contents and stakeholders involved in marketing model, vision analysis and scorecards belongs to the database module, architecture can be incorporated into the decision-making part of the model by using the theory of distribute system from Figure 5 . Enterprise can make rapid response to changes and competition by taking advantage of cloud computing and big 

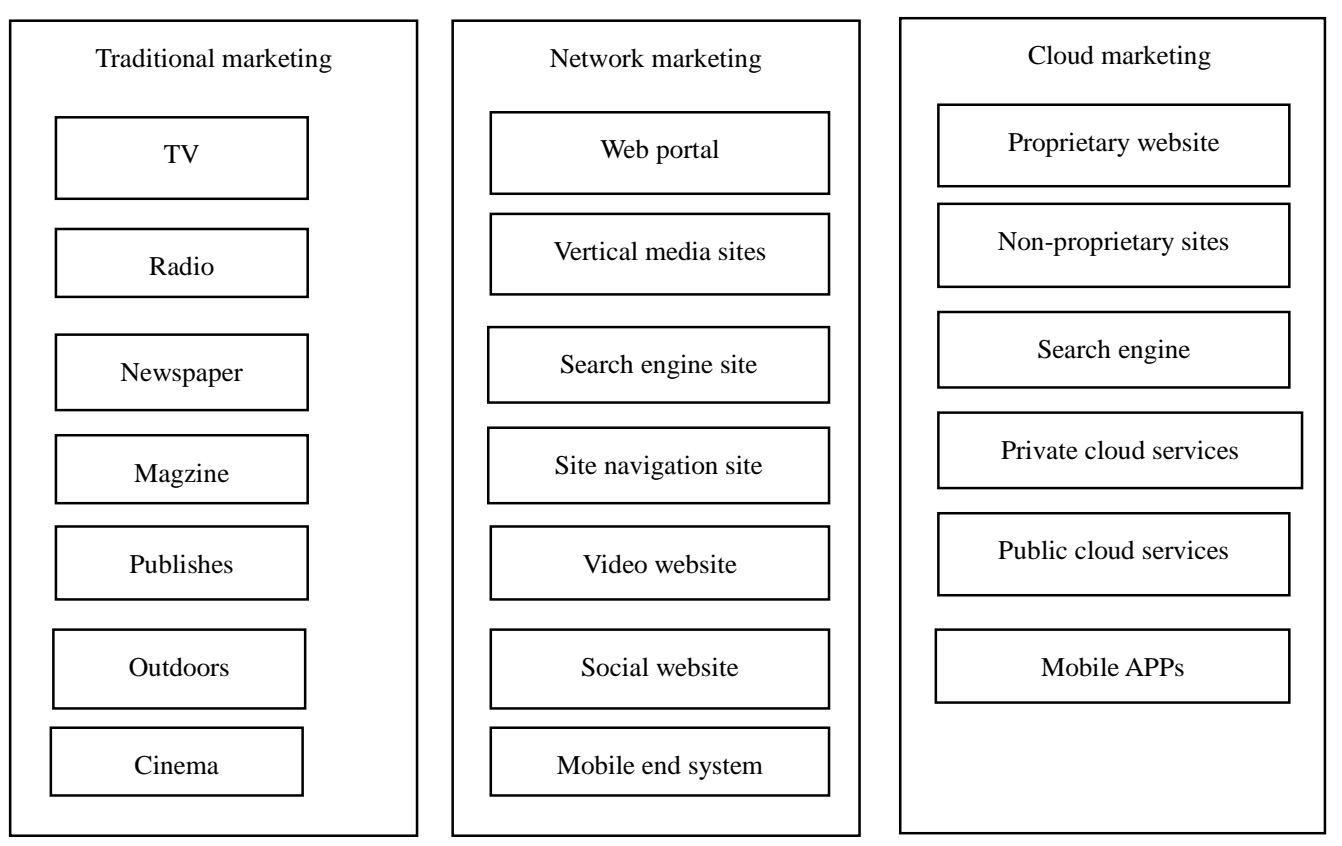

Figure 3. Enterprise marketing methods.

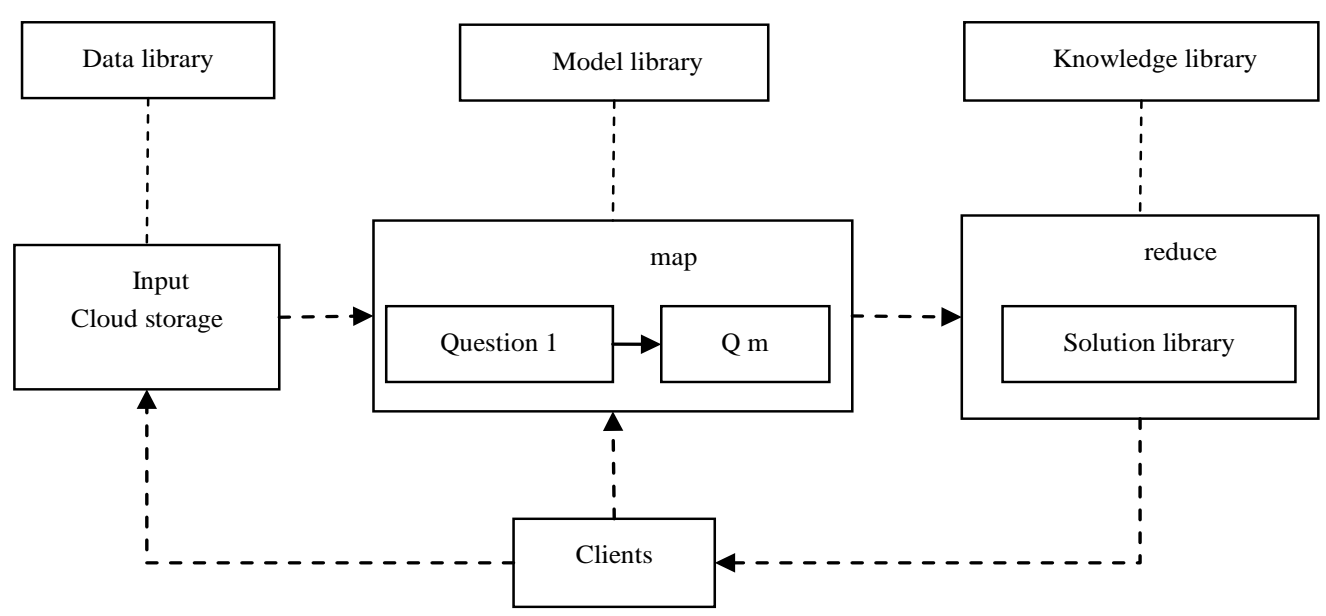

Figure 4. C-marketing program.

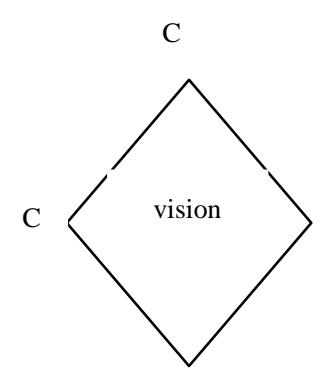

C

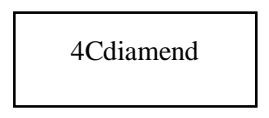

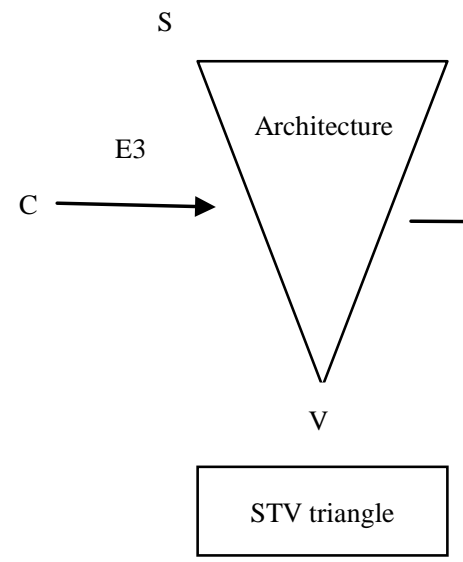

$\mathrm{T}$

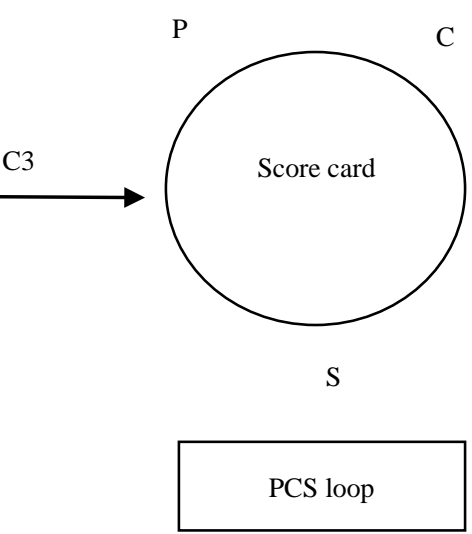

Figure 5. marketing model. Source: Philip Kotler and Hermawan Kartajaya, Reposition Asia: From Bubble to Sustainable Economy, John Wiley \& Sons (Asia) Pte Ltd, 2000. 


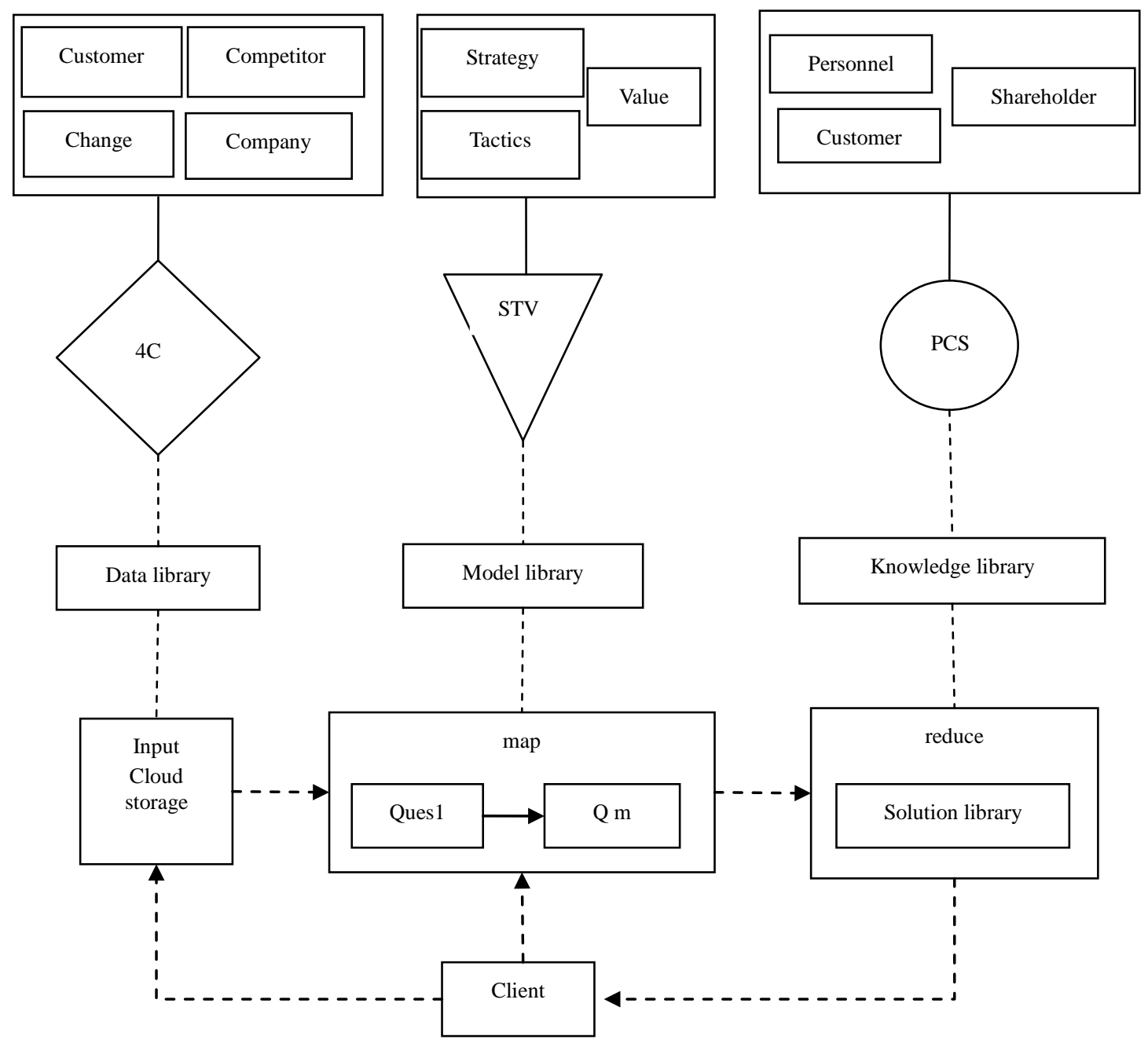

Figure 6. Improved C-Marketing.

data processing capabilities. Figure 6 shows that we can find a way to solve marketing problems by cloud computing.

\subsection{Cloud Marketing Advantages}

For businesses, the biggest advantage of cloud marketing is undoubtedly the cost advantage, implementing cloud marketing and cloud management can save numerous advertising, promotion, marketing expenses for enterprise. From other sides, cloud marketing advantages include: manpower savings, cloud computing applications is on the basis of the computer, whose core is large data computing capabilities so that it can be a large cost savings for the enterprise; easy and simple to handle, cloud computing may produce some difficulties for enterprise at the beginning of the introduction, but once familiar, as the cloud computing is fully computer automatic mode, which needs just a few operators, and easy to operate; precise personalized services, cloud computing uses distributed computing principles, make a personalized ser- vice for each customer, which can better fit the spending habits of consumers and meet consumer demands.

\section{Conclusion}

The popularity degree of cloud marketing is not as much as cloud computing so far, although cloud computing is a hot research topic. This paper summarizes the difference between cloud marketing and traditional network marketing, and introduces marketing advantages of cloud marketing to enterprises for providing a theoretical basis for enterprises to implement cloud marketing. Enterprises and academics should spend more time on marketing model designing of cloud computing to bring more benefits for enterprises.

\section{Funding}

This work is supported by the National Natural Science Foundation of China (NO.61075115), Innovation Projects of Shanghai University of Engineering Science 
(13KY0323) and Innovation Program of Shanghai Municipal Education Commission (Grant No.12ZZ185).

\section{REFERENCES}

[1] Y. Kang, "Development of Network Marketing,” Renmin University of China Press, Beijing, 2004, 147-149

[2] C. Wang, "On Network Marketing in the new situation," Chinese Market, Vol. 29, 2013, pp. 42-43

[3] R. J. Zhang, "Discussion about enterprise e-commerce network marketing," Enterprise Management, Vol. 9, 2013, pp. 30-31.

[4] Q. Zhang, “Apparel Consumer Behavior in E-Commerce Environment,” Electronic Design Engineering, Vol. 7, 2013, pp. 52-54

[5] Z. C. Li and M.-L. Liu, "Consumer Behavior Study under E-Commerce Environment,” China Management Science, Vol. 10, 2002, pp. 88-91

[6] Y. Wei, "Research of Consumer Behavior in Network Group Buying,” Ecommerce, Vol. 11, 2011, pp. 85-86.

[7] P. Gao, "Development Countermeasure of Network Marketing,” Business Research, Vol. 3, 2002, pp. 58-61.

[8] Z. Yang and L. Gao, "Innovative model direction of SME network marketing," East China Economic Management, Vol. 10, 2004, pp. 73-75.

[9] W. Tao, "SME Network Marketing Situation, Problems and Countermeasures,” Marketing Strategy, Vol. 12, 2012, pp. 122-123.

[10] J. J. Zhang, "Summary of E-Commerce Joint Distribution,” Ecommerce, Vol. 9, 2013, pp. 87-90.

[11] Y. Ren, "Network Marketing Channel Under E-Commerce Mode,” Intelligence Magazine, Vol. 1, 2004, pp. 79-80.

[12] K. Sims, "IBM Introduces Ready-To-Use Cloud Computing Collaboration Services Get Clients Started with Cloud Computing," 2007. http://www-03.ibm.com/press/us/en/presselease/22613.ws $\underline{\mathrm{S}}$

[13] G. Boss, P. Malladi, D. Quan, L. Legregni and H. Hall, "Cloud Computing," IBM White Paper, 2007. http://download.boulder.ibm.com/ibmdl/pub/software/dw/ wes/hipods/Cloud_computing_wp_final_8Oct.pdf
[14] M. Mowbray and S. Person, “A Client-Based Privacy Manager for Cloud Computing," Proceedings of the 4th International ICST Conference on Communication System Soft Ware and Middleware, 2009, pp. 1-8.

[15] S. Pearson, "Taking Account of Privacy When Designing Cloud Computering Service,” Proceeding of the 2009 ICSE Workshop on Software Engineering Challenges of Cloud Computing, 2009, pp. 44-52.

[16] D. Bernstein and E. Ludvigson, "Networking Challenges and Resultant Approaches for Large Scale Cloud Construction," Pervasive Computing Conference GPC, Geneva, 4-8 May 2009, pp. 136-142.

[17] D. Bernstein, E. Ludvigson, K. Sankar, et al., "Blueprint for the Intercloud-Protocols and Formats for Cloud Computing Interoperability," Proceedings of the 2009 4th International Conference on Internet and Web Applications and Services, Venice, 24-28 May 2009, pp. 328336.

[18] M. Matos, A. Sousa, J. Pereira, et al., "CLON: Overlay Network for Clouds," Proceedings of the 3rd Workshop on Dependable Distributed Data Management, Nuremberg, 2009, pp. 14-17.

[19] M. Descher, P. Masser, T. Feilhauer, et al., "Retaining Data Control to the Client in Infrastructure Clouds," International Conference on Acailibility, Reliability and Security (ARES’09), Fukuoka, 16-19 March 2009, pp. 916.

[20] T. Hirofuchi, H. Ogawa, H. Nakada, et al., "A Live Storage Migration Mechanisa over Wan for Relocatable Virtual Machine Services on Clouds," Proceedings of the 2009 9th IEEE/ACM International Symposium on Cluster Computing and the Grid, Shanghai, 18-21 May 2009, pp. 460-465.

[21] L. Hu, S. Ying, X. Jia, et al., "Towards an Approach of Semantic Access Control," Proceedings of the 1st International Conference Cloud Computing, Beijing, 1-4 December 2009, pp. 145-156.

[22] P. Liu, “Three Reference Standards for Determining Cloud Computing," Cloud Computing, Vol. 10, 2010, pp. 58-59.

[23] P. Kotler, "Rethinking Marketing: Sustainable Marketing Enterprise in Asia,” China Renmin University Press, Beijing, 2004. 